\title{
Vibrational analysis of different crystalline phases of the organic electroluminescent material tris(8-hydroxyquinolinato)aluminum(III)
}

\section{$\left(\mathrm{Alq}_{3}\right)$}

\author{
Michael Cölle,* Stefan Forero-Lenger, Jürgen Gmeiner and Wolfgang Brütting ${ }^{(+)}$ \\ Experimental Physics II, University of Bayreuth, 95440 Bayreuth, Germany \\ Tel: +49 92155 2602,fax: +4992155 2621,e-mail:michael.coelle@uni-bayreuth.de \\ (+) present address: University of Augsburg, Experimental Physics IV, 86135 Augsburg, Germany; \\ E-mail: wolfgang.bruetting@physik.uni-augsburg.de
}

\begin{abstract}
Applying infrared (IR) spectroscopy on two different crystalline phases of tris(8hydroxyquinolinato)aluminum(III) $\left(\alpha-\mathrm{Alq}_{3} \text { and } \delta \text {-Alq }\right)_{3}$ the isomerism of the $\mathrm{Alq}_{3}$ molecule was investigated. Significant differences between the two phases were found in the IR spectra, which can be explained in terms of the different symmetries of the facial and meridional isomer. Additionally, intermolecular interactions of the Alq3-molecules due to crystallinity have been taken into account. The results prove that $\alpha-\mathrm{Alq}_{3}$ consists of the meridional isomer while the recently discovered blue luminescent $\delta$-phase is composed of the facial isomer of the $\mathrm{Alq}_{3}$ molecule.
\end{abstract}




\section{Introduction}

After more than 10 years of intense research and development of organic light-emitting diodes (OLEDs), $\mathrm{Alq}_{3}$ still continues to be the workhorse among the class of low-molecular weight materials for OLEDs. ${ }^{1,2}$ However, a still unresolved issue concerns the isomery of the $\mathrm{Alq}_{3}$ molecule. ${ }^{3,4}$ It is well-known that octahedral complexes of the type $\mathrm{MN}_{3} \mathrm{O}_{3}$, where $\mathrm{M}$ is a trivalent metal and $\mathrm{N}$ and $\mathrm{O}$ stand for the nitrogen and oxygen atoms in the hydroxyquinoline ligands, can occur in two different geometrical isomers: meridional (mer) and facial $(f a c)$. Nevertheless only the meridional isomer has been clearly identified so far. Therefore, it is generally believed that the meridional isomer is predominant, both in amorphous films and crystals of $\mathrm{Alq}_{3} .^{5,6}$

The existence and the properties of the facial isomer are intensely discussed in the literature. ${ }^{3,6-12} \mathrm{~A}$ key issue concerning sublimed $\mathrm{Alq}_{3}$ films is the possible presence of the facial isomer, which is expected to cause structural defects in the film and to be an efficient electron trap. Its influence on trap density, charge carrier transport and thus on the characteristics and performance of OLEDs has been suggested, ${ }^{13-15}$ but until recently no direct experimental evidence for the facial isomer has been found. Thus the isolation of the facial isomer is of high interest, as it allows to examine its properties separately and to clarify its role in OLEDs.

In a previous publication we have reported a new crystalline phase of $\mathrm{Alq}_{3}\left(\delta-\mathrm{Alq}_{3}\right)$, exhibiting strongly blue-shifted fluorescence. ${ }^{16,19}$ Structural investigations have proved that it consists of the facial isomer of the $\mathrm{Alq}_{3}$ molecule. ${ }^{21}$ In this paper we present a comparison of the infrared (IR) spectra of the well-known $\alpha$-phase of $\mathrm{Alq}_{3}$ being known to contain the meridional isomer to the new $\delta$-phase and demonstrate that their vibrational properties are consistent with the isomery of the $\mathrm{Alq}_{3}$ molecule.

Due to the different molecular symmetry of the meridional and facial isomers $\left(\mathrm{C}_{1}\right.$ versus $\left.\mathrm{C}_{3}\right)$ the 
vibrational analysis using IR spectroscopy should be one possible way to differentiate them. Especially the central part of the molecule $\mathrm{AlO}_{3} \mathrm{~N}_{3}$ should show characteristic vibrational properties for each isomer (Al-O and Al-N modes located below $600 \mathrm{~cm}^{-1}$ ), which were calculated by Kushto et al. ${ }^{6}$ Further, there is a weak coupling of the three ligands via the central part and motions around the central aluminum atom participate in most of the molecular vibrations below $1700 \mathrm{~cm}^{-1}$. This coupling depends on the relative positions of the oxygen atoms of the ligands. For the facial isomer each oxygen atom faces a nitrogen atom thus the coupling via the Al atom is identical for all ligands (see Figure 1). For the meridional isomer, however, the coupling mainly affects the ligand B and $\mathrm{C}$, where the oxygen atoms face each other and to a lesser extend the A and B ligands, which have the oxygen and nitrogen atoms opposite. The coupling mechanism of ligand $\mathrm{A}$ and $\mathrm{C}$ is mainly characterized by the modes of the two opposite nitrogen atoms. This means, that due to a lower symmetry of the meridional molecule each vibrational mode has a slightly different energy for the three ligands.

Degli Esposti et al. published a detailed theoretical study of the vibrational properties of the meridional $\mathrm{Alq}_{3}$-molecule. ${ }^{17}$ For the first time the coupling terms between the three ligands have explicitely been taken into account. This interaction of the ligands, mainly via the Al-bonds is expected to be different for the two isomers. An important result is a well-founded understanding of the IR spectra of mer-Alq 3 with the possibility to attribute lines to the three different ligands A, B and C. On the base of this detailed theoretical work we will first discuss our experimental results on polycrystalline $\mathrm{Alq}_{3}$ for the entire spectrum up to $1700 \mathrm{~cm}^{-1}$. Thereafter we will focus on the stretching modes around the aluminum atom (below $600 \mathrm{~cm}^{-1}$ ) before investigating the influence of crystallinity on the vibrational spectra. 


\section{Experimental}

Polycrystalline samples of the $\alpha$ - and $\delta$-phase of $\mathrm{Alq}_{3}$ were fabricated in a temperature gradient sublimation apparatus as described elsewhere. ${ }^{16}$ Thereby we obtained the usual yellowish-green $\alpha$ $\mathrm{Alq}_{3}$ as the main phase together with small amounts of $\delta$-Alq 3 growing in the hot zone of the sublimation tube. We note that $\delta$-Alq ${ }_{3}$ can also be obtained by annealing $\alpha$-Alq 3 above $385^{\circ} \mathrm{C} .{ }^{18,19}$ Measurements on samples fabricated by this annealing process gave the same spectra and led to the same results. The phases have been clearly identified by x-ray powder diffraction measurements. ${ }^{16,19,20}$ If not marked otherwise, polycrystalline samples as obtained from the sublimation tube have been measured. Powder samples were made by smoothly rubbing the polycrystalline samples mechanically. The Alq 3 -samples were measured on $\mathrm{KBr}$ pellets in a Bruker IFS55 Fourier transform infrared (FT-IR) spectrometer with $\mathrm{KBr}$ beamsplitters and a resolution of $2 \mathrm{~cm}^{-1}$. Additionally, to prove the interpretation below $420 \mathrm{~cm}^{-1}$, a Bruker IFS $66 \mathrm{v}$ spectrometer with PE-beamsplitters, CsI pellets and a resolution of $1 \mathrm{~cm}^{-1}$ was used for the low energy region between 370 and $480 \mathrm{~cm}^{-1}$. We note that all spectra shown here are raw data, without any further correction (smoothing, background, etc.). In the case of the polycrystalline samples scattering due to crystallinity is responsible for the broad background with sometimes asymmetric peaks. As will be seen from the comparison to the powder measurements this does not significantly influence the peak position.

\section{Results and Discussion}

The IR spectra of the polycrystalline $\alpha$ - and $\delta$-phases of $\mathrm{Alq}_{3}$ are shown in Figure 2 together with the spectra of the free-base ligand 8-hydroxyquinoline (8-Hq). 8-Hq shows intense lines above $700 \mathrm{~cm}^{-1}$. Thus it is obvious that for $\mathrm{Alq}_{3}$ the region above $700 \mathrm{~cm}^{-1}$ is dominated by the ligand vibrations, 
whereas below $600 \mathrm{~cm}^{-1}$ the central part around the Al-atom becomes more important. The spectra of the $\alpha$ - and $\delta$-phases of $\mathrm{Alq}_{3}$ show significant differences which will be discussed below following theoretical calculations by Degli Esposti et al. ${ }^{17}$ and Kushto et al. ${ }^{6}$ Table 1 summarizes the band positions and their relative intensities together with their preliminary assignments according to References 6 and 17 for the mer-Alq 3 molecule, which is the constituent of $\alpha$-Alq $3 .{ }^{5,6}$ For the $\delta$ phase of $\mathrm{Alq}_{3}$ we know from structural investigations that it consists of the facial isomer. We can therefore use the IR spectra to identify characteristic differences in their vibrational properties.

As can be seen in Figure 2 most of the bands in $\delta$-Alq 3 have slightly reduced line width. Furthermore, broad featureless bands in $\alpha-\mathrm{Alq}_{3}$ become narrower and exhibit pronounced structures in $\delta$-Alq ${ }_{3}$, in particular some adjacent bands in $\alpha$-Alq ${ }_{3}$ become one single peak in $\delta$-Alq ${ }_{3}$. Examples are found at wavenumbers $1470 \mathrm{~cm}^{-1}, 1380 \mathrm{~cm}^{-1}, 1333 \mathrm{~cm}^{-1}, 864 \mathrm{~cm}^{-1}, 750 \mathrm{~cm}^{-1}$, and $638 \mathrm{~cm}^{-1}$. According to Degli Esposti et al. the broad band of $\alpha-\mathrm{Alq}_{3}$ at $645 \mathrm{~cm}^{-1}$ consisting of peaks at $652 \mathrm{~cm}^{-}$ ${ }^{1}, 647 \mathrm{~cm}^{-1}, 640 \mathrm{~cm}^{-1}$ and the small shoulder at about $625 \mathrm{~cm}^{-1}$ are due to the pyramidalization mode of the nitrogen atoms within the different ligands $\mathrm{A}, \mathrm{B}$ and $\mathrm{C}$ under participation of Al-O stretching. Whereas the modes at $652 \mathrm{~cm}^{-1}$ to $640 \mathrm{~cm}^{-1}$ are mainly due to torsional and pyramidalization modes of ligand $\mathrm{C}$, the shoulder at $625 \mathrm{~cm}^{-1}$ originates mainly from ligand $\mathrm{A}$ indicating the inequivalence among the ligands in mer-Alq ${ }_{3}$. In $f a c-\mathrm{Alq}_{3}$ the ligands are equivalent and therefore the low frequency shoulder should not be observed in $\delta$-Alq $\mathrm{q}_{3}$. We also note that the whole band is narrower for the $\delta$-phase with a full width at half maximum (FWHM) of $28 \mathrm{~cm}^{-1}$ and $19 \mathrm{~cm}^{-1}$ for $\alpha$ - and $\delta$ $\mathrm{Alq}_{3}$, respectively. For $\alpha-\mathrm{Alq}_{3}$, the band centered at $747 \mathrm{~cm}^{-1}$ consists of two overlapping bands, one involving $\mathrm{C}-\mathrm{C}^{\mathrm{ABC}}$ stretching under participation of Al-O stretching on the low frequency side and a second one involving $\mathrm{C}-\mathrm{C}^{\mathrm{ABC}}$ deformations on the high frequency side. Each of the bands consists of contributions from ligands A, B and C. Taking all together A-vibrations are found at the flanks and C-vibrations in the center of the whole band. Contributions from B are in between the 
contributions of $\mathrm{A}$ and $\mathrm{C}$. If one also takes into account a possible splitting due to the crystal field it is clear why this band is so broad. In contrast for $\delta$-Alq 3 the FWHM again is smaller $\left(\alpha: 40 \mathrm{~cm}^{-1}, \delta\right.$ : $17 \mathrm{~cm}^{-1}$ ) and two peaks are clearly resolved. As for $f a c-\mathrm{Alq}_{3}$ the ligands are equivalent and only one peak is expected; therefore the observed splitting can be attributed to a crystalline effect (this will be discussed in more detail later on).

Weak but interesting bands are observed at $867 \mathrm{~cm}^{-1}$ and $859 \mathrm{~cm}^{-1}$ for $\alpha-\mathrm{Alq}_{3}$ and assigned to torsional and pyramidalization modes of the different ligands. The peak at $867 \mathrm{~cm}^{-1}$ is due to vibrations of ligand $\mathrm{B}$, while the peak at $859 \mathrm{~cm}^{-1}$ originates from vibrations of ligands $\mathrm{A}$ and $\mathrm{C}$. For $\delta$-Alq ${ }_{3}$, however, instead of this splitting only one single peak at $864 \mathrm{~cm}^{-1}$ is observed. The difference between the ligands seems indeed to be repealed in $\delta$-Alq $\mathrm{Al}_{3}$ as expected for the facial isomer. The superposition of two peaks at $1332 \mathrm{~cm}^{-1}$ and $1327 \mathrm{~cm}^{-1}$ results in a broad band for $\alpha-\mathrm{Alq}_{3}$. This band is a result of $\mathrm{CCH}^{\mathrm{ABC}}$ bending modes of the different ligands and $\mathrm{C}-\mathrm{O}^{\mathrm{ABC}}$ stretching modes. Theoretically the C-O stretching bands of ligand A and $\mathrm{C}$ are separated by more than $6 \mathrm{~cm}^{-1}$. The CO stretching mode of ligand $\mathrm{A}$ is located at the high frequency side and the $\mathrm{C}-\mathrm{O}$ stretching mode of ligand $\mathrm{C}$ at the low frequency side of this band. Consequently a broad band is observed in the IRspectrum. Instead of this broad feature there is only one peak for $\delta$-Alq 3 located at $1333 \mathrm{~cm}^{-1}$. This is another clear hint for the equivalence of vibrational modes in the three ligands of the facial isomer in the $\delta$-phase.

For the doubled band observed at about $1380 \mathrm{~cm}^{-1}$ in $\alpha-\mathrm{Alq}_{3}$ splittings of $2-3 \mathrm{~cm}^{-1}$ are predicted due to $\mathrm{C}-\mathrm{C}^{\mathrm{ABC}}$ and $\mathrm{C}-\mathrm{N}^{\mathrm{ABC}}$ stretch vibrations in the different ligands which are not resolvable. The clear doublets in both crystalline phases ( $\alpha$ and $\delta$ ) are thus attributed again to a crystalline effect as will be discussed later. Another intense and broad feature is observed for $\alpha-\mathrm{Alq}_{3}$ at $1468 \mathrm{~cm}^{-1}$, being the superposition of $\mathrm{C}-\mathrm{O}^{\mathrm{ABC}}$ and $\mathrm{C}-\mathrm{C}^{\mathrm{ABC}}$ stretching vibrations in the ligands $\mathrm{A}, \mathrm{B}$ and $\mathrm{C}$ of the 
meridional molecule. Theoretical energetic distances between these contributions are $4 \mathrm{~cm}^{-1}$ and $8 \mathrm{~cm}^{-}$ ${ }^{1}$ resulting in one broad band. For $\delta$-Alq ${ }_{3}$ again only one peak is expected and observed at $1473 \mathrm{~cm}^{-1}$. The weak low frequency shoulder in both phases is assigned to $\mathrm{C}-\mathrm{H}$ bending.

Kushto et al. calculated the IR-spectra of the facial and the meridional isomer. ${ }^{6}$ Characteristic differences were predicted at about $400 \mathrm{~cm}^{-1}$ and $550 \mathrm{~cm}^{-1}$. Theoretically, a much more intense peak at $406 \mathrm{~cm}^{-1}$ is expected for the $f a c-\mathrm{Alq}_{3}$ compared to mer-Alq $\mathrm{A}_{3}$. Indeed this is observed experimentally for the band at $397 \mathrm{~cm}^{-1}$. Further they found the characteristic feature of two neighbored peaks at $550 \mathrm{~cm}^{-1}$ for the meridional molecule and only one peak for the facial molecule to be most significant to distinguish between the two isomers. As shown in Figure 2 one observes exactly this characteristic difference between $\alpha$ - and $\delta$-Alq.

Further arguments for different isomers in $\alpha$ - and $\delta$-Alq come from symmetry considerations of the central fragment around the Al-atom. As discussed above the differences in the IR spectra of the two phases, in particular the higher number of IR-active vibrational modes for the $\alpha$-phase in comparison to the $\delta$-phase of $\mathrm{Alq}_{3}$, can be ascribed to the different symmetry of the constituting meridional and facial isomers, namely $\mathrm{C}_{1}$ and $\mathrm{C}_{3}$, respectively. Focusing on the central fragment $\mathrm{AlO}_{3} \mathrm{~N}_{3}$, the local symmetry for both isomers is $\mathrm{C}_{2 \mathrm{v}}$ and $\mathrm{C}_{3 \mathrm{v}}$, respectively, as shown in Figure 3 . The separation of the central part from the ligands is justified by the different and well separated vibrational energies belonging to these groups, as observed in the comparison of $\mathrm{Alq}_{3}$ with the hydroxyquinoline parent of the ligands (see Ref. 22). Thus IR-modes that belong to the $\mathrm{AlO}_{3} \mathrm{~N}_{3}$ group are found predominantly in the region below $600 \mathrm{~cm}^{-1}$. In particular we observe in our experiment the stretching vibrations. For $\alpha-\mathrm{Alq}_{3}$, which consists of the mer-Alq $\mathrm{q}_{3}$ isomer $\left(\mathrm{C}_{2 \mathrm{v}}\right)$ six stretching vibrations are expected, three involving Al-N and three involving Al-O modes (see figure 3). As they are all dipole allowed, they are observable by IR-spectroscopy. According to Ref. 6 we make the following assignments for $\alpha-\mathrm{Alq}_{3}$ : Al-N stretching: $396 \mathrm{~cm}^{-1}, 405 \mathrm{~cm}^{-1}, 418 \mathrm{~cm}^{-1}, \mathrm{Al}-\mathrm{O}$ 
stretching: $522 \mathrm{~cm}^{-1}, 542 \mathrm{~cm}^{-1}, 549 \mathrm{~cm}^{-1}$. By contrast $\delta$-Alq $\mathrm{q}_{3}$ shows a total of only four bands in this region $\left(397 \mathrm{~cm}^{-1}, 423 \mathrm{~cm}^{-1}, 531 \mathrm{~cm}^{-1}, 548 \mathrm{~cm}^{-1}\right)$. As the $\mathrm{AlO}_{3} \mathrm{~N}_{3}$ fragment of the facial isomer belongs to symmetry $\mathrm{C}_{3 \mathrm{v}}$ also six stretching vibrations are expected but four of them belong to two degenerate vibrational states and therefore only four bands should be observed in IR-spectroscopy as one does for $\delta$-Alq 3 . The Al-N stretching is found at $397 \mathrm{~cm}^{-1}$ and $423 \mathrm{~cm}^{-1}$, the Al-O stretching at $531 \mathrm{~cm}^{-1}$ and $548 \mathrm{~cm}^{-1}$. The degeneracy of the first and last band are lifted in the $\alpha$-phase of $\mathrm{Alq}_{3}(\mathrm{see}$ Figure 3 and Figure 2 incl. inset), which consists of the meridional isomer, in agreement with theoretical calculations of Kushto et al.

A further point to consider is the fact, that vibrational studies of the polycrystalline phases of $\mathrm{Alq}_{3}$ do not only involve the intramolecular characteristics but also the effect of crystallinity of the sample. Therefore, in Figure 4 we compare IR-spectra of polycrystalline samples to very fine powders of the $\alpha$ - and $\delta$-phases. The upper trace shows the polycrystalline samples as prepared and the lower trace the same samples after smoothly rubbing them directly on the $\mathrm{KBr}$ pellets, giving a very fine powder. We note that less crystallinity of the samples is also reducing the background due to scattering, especially in the higher energy region above $700 \mathrm{~cm}^{-1}$ resulting in symmetric peaks in the measured spectrum. Nevertheless, the energetic positions of the peaks are essentially not affected by the sample crystallinity.

We observe two distinct effects: At first the bands above $600 \mathrm{~cm}^{-1}$ and therefore the vibrational modes originating mainly from the hydroxyquinoline ligands become sharper and the lines at 750 and $1380 \mathrm{~cm}^{-1}$ lose their doublet character after rubbing. This is attributed to the intermolecular loss of geometric correlation. Secondly we note that the Al-N and Al-O stretching vibrations found in the $\alpha$ - and $\delta$-crystals stay, apart from slight shifts, at the same frequency after disintegration of the crystals. The degenerated bands of the facial isomer at $397 \mathrm{~cm}^{-1}$ and $548 \mathrm{~cm}^{-1}$ still are one single peak for the $\delta-\mathrm{Alq}_{3}$ and split into two distinct peaks for the meridional $\alpha-\mathrm{Alq}_{3}$ respectively. Thus the 
differences between the $\delta-\mathrm{Alq}_{3}$ and the $\alpha-\mathrm{Alq}_{3}$ are not related to the crystallinity or packing but due to the difference in the symmetry of the molecules.

One significant change between the crystalline and the powder spectra of $\delta$-Alq $\mathrm{A}_{3}$ is the large loss of intensity of the Al-O band at $531 \mathrm{~cm}^{-1}$, which corresponds to the redshifted mode at $522 \mathrm{~cm}^{-1}$ in $\alpha$ $\mathrm{Alq}_{3}$. From theoretical considerations the intensity of the Al-O streching mode for the facial isomer at $531 \mathrm{~cm}^{-1}$ is expected to be very small. ${ }^{6}$ This is indeed observed in the spectrum of the very fine powder in Figure 4a. It is, however, well known, that molecular ordering in a crystalline environment can change the relative intensities of related vibronic bands, e.g. due to dipole-dipole interaction. ${ }^{23-25}$ The strength of this effect depends on the relative orientation of the dipoles, their distance $r\left(\sim r^{-3}\right)$, the difference of the squares of their transition energies and their oscillator strength. Unfortunately the absolute values for the oscillator strength can not simply be obtained from the IRspectra $^{26}$ and thus it is not possible to make quantitative calculations. But considering the relative positions of the molecules in the crystal known from structural analysis ${ }^{5,21}$ one can roughly estimate that this effect should be more pronounced for the facial isomer in the $\delta$-phase. Thus the band at $531 \mathrm{~cm}^{-1}$ can be viewed as a kind of crystallinity band of $\delta-\mathrm{Alq}_{3}$.

Further it is clearly observed that the doubling of the band centered at $750 \mathrm{~cm}^{-1}$ in $\delta$-Alq ${ }_{3}$ disappears after destroying the crystallinity of the sample, confirming the assignment made in the first part of this work. The same holds for the double band observed for both phases at about $1380 \mathrm{~cm}^{-1}$. It also becomes a single mode after powdering. We note that although all vibrational peaks of both isomers become narrower after mechanical treatment, essential bands in $\alpha$-Alq 3 remain broader than in $\delta$ $\mathrm{Alq}_{3}$, accounting for the inequivalence of the $\mathrm{A}, \mathrm{B}$ and $\mathrm{C}$ ligands in mer-Alq $\mathrm{A}_{3}$ Examples are the lines at the region of $640 \mathrm{~cm}^{-1}, 1333 \mathrm{~cm}^{-1}$ and $1470 \mathrm{~cm}^{-1}$ with FWHM of $17 \mathrm{~cm}^{-1}, 12 \mathrm{~cm}^{-1}, 13 \mathrm{~cm}^{-1}$ and $20 \mathrm{~cm}^{-}$ ${ }^{1}, 15 \mathrm{~cm}^{-1}, 19 \mathrm{~cm}^{-1}$ for the $\delta-$ and the $\alpha-\mathrm{Alq}_{3}$ respectively. As the intramolecular geometry is retained 
after making the fine powder we note that the removal of crystallinity (seen above $600 \mathrm{~cm}^{-1}$ ) permits us to clearly identify the differences in the central $\mathrm{AlO}_{3} \mathrm{~N}_{3}$ part of the $\mathrm{Alq}_{3}$ molecules below $600 \mathrm{~cm}^{-1}$. Therefore it is evident that the meridional molecule constitutes the $\alpha$-phase and the facial molecule the $\delta$-phase of $\mathrm{Alq}_{3}$.

\section{Conclusion}

In conclusion we presented the first IR-measurements on the blue luminescent $\delta$-phase of $\mathrm{Alq}_{3}$. From a thorough comparison with theoretical work by Kushto et al. ${ }^{6}$ and Degli Esposti et al. ${ }^{17}$, together with an explicit consideration of the symmetry of the central fragment $\mathrm{AlO}_{3} \mathrm{~N}_{3}$ as well as the influence of crystallinity we have convincing evidence that the $\delta$-phase of $\mathrm{Alq}_{3}$ contains the facial isomer, which is also consistent with structural investigations. Both isomers (mer and fac$\left.\mathrm{Alq}_{3}\right)$ show characteristic differences in their vibrational spectra that can be used like fingerprints to distinguish and to identify them. From these findings it should now be possible to examine the importance of the isomerism of the $\mathrm{Alq}_{3}$ molecule, e.g. for the growth and structural properties of thin films, and to specify its role in OLEDs. 


\section{REFERENCES}

(1) Tang, C.W.; VanSlyke, S.A.; Appl. Phys. Lett. 1987, 51, 913.

(2) Brütting, W.; Berleb, S.; Mückl, A. Organic Electronics 2001, 2, 1.

(3) Curioni, A.; Boero, M.; Andreoni, W. Chem. Phys. Lett. 1998, 294, 263.

(4) Martin, R.; Kress, J.; Campbell, I.; Smith, D. Phys. Rev. B 2000, 61, 15804.

(5) Brinkmann, M.; Gadret, G.; Muccini, G.; Taliani, C.; Masciocchi, N.; Sironi, A. J. Am. Chem. Soc. 2000, 122, 5147.

(6) Kushto, G.; Iizumi, Y.; Kido, J.; Kafafi, Z. H., J. Phys. Chem. A 2000, 104, 3670.

(7) Ichikawa, H.; Shimada, T.; Koma, A., Jpn. J. Appl. Phys. 2 2001, 40, 225.

(8) Baker, B. C.; Sawyer, D. T., Anal. Chem. 1968, 40, 1945.

(9) Majer, J.; Reade, M., Chem. Comm. 1970, 1, 58.

(10) Sugimoto, M.; Sakaki, S.; Sakanoue, K.; Newton, M. D., J. Appl. Phys. 2001, 90, 6092.

(11) Amati, M.; Lelj, F.; Chem. Phys. Lett. 2002, 358, 144.

(12) Amati, M.; Lelj, F.; Chem. Phys. Lett. 2002, 363, 451.

(13) Burrows, P.E.; Shen, Z.; Bulovic, V.; McCarty, D.M.; Forrest, S.R.; Cronin, J.A.; Thompson, M.E., J. Appl. Phys. 1996, 79, 7991.

(14) Steiger, J.; Schmechel, R.; von Seggern, H., Synth. Met. 2002, 129, 1.

(15) Malliaras, G. G.; Shen, Y.; Dunlap, D. H.; Murata, H.; Kafafi, Z. H., Appl. Phys. Lett. 2001, 79, 2582. 
(16) Braun, M.; Gmeiner, J.; Tzolov, M.; Cölle, M.; Meyer, M.; Milius, W.; Hillebrecht, H.; Wendland, O.; von Schütz, J.; Brütting, W., J. Chem. Phys. 2001, 114, 9625.

(17) Degli Esposti, A.; Brinkmann, M.; Ruani, G., J.Chem. Phys. 2002, 116, 798.

(18) Cölle, M.; Gmeiner, J.; Milius, W.; Hillebrecht, H.; Brütting, W., Proceedings EL2002 (Ghent, Belgium) 2002, 133.

(19) Cölle, M.; Gmeiner, J.; Milius, W.; Hillebrecht, H.; Brütting, W., Adv. Funct. Mater. 2003, in press.

(20) Although the phases have been clearly distinguished by X-ray diffraction measurements some small admixtures of a few percent can not be excluded.

(21) Cölle, M.; Dinnebier R.E.; Brütting, W., Chem. Comm., 2002, 23, 2908.

(22) Larsson, R.; Eskilsson, O., Acta Chem. Scan. 1968, 22, 1067

(23) Rhodes, W.; J. Am. Chem. Soc. 1961, 83, 3609.(24) Tinoco, I., J. Am. Chem. Soc. 1960, 82, 4785.

(25) Bradley, D.D.C., J. Phys. D, 1987, 20, 1389.

(26) Person, W.B.; Zerbi, G., Vibrational intensities in infrared and raman spectroscopy, 1982, elsevier scientific publishing, New York. 
TABLE 1: Comparison of the experimental frequencies of the $\delta$-phase $(E(\delta))$, the $\alpha$-phase $(E(\alpha))$ and 8-hydroxyquinoline $\left(\mathrm{E}_{\text {quin }}\right)$ together with the assignments according to Ref. 6 and 17. A, B and C refer to the corresponding ligands in $m e r-\mathrm{Alq}_{3}$. Theoretical frequencies for the mer-Alq 3 are listed under $\left(\mathrm{E}_{\mathrm{calc}}\right)$. In the last column the normal modes of 8-hydroxyquinoline are labeled by the symmetry within the $C_{S}$ group. Relative intensities for the $\delta$ - and the $\alpha$-phase are given in column $\mathrm{I}(\delta)$ and $\mathrm{I}(\alpha)$. Asterisks mark peaks related to crystallinity.

\begin{tabular}{|c|c|c|c|c|c|c|c|c|c|}
\hline No. & $\begin{array}{l}\mathrm{E}(\delta) \\
{\left[\mathrm{cm}^{-1}\right]}\end{array}$ & $\begin{array}{l}\mathrm{I}(\delta) \\
\text { [a.u.] }\end{array}$ & Mode & $\begin{array}{l}\mathrm{E}(\alpha) \\
{\left[\mathrm{cm}^{-1}\right]}\end{array}$ & $\begin{array}{l}\mathrm{I}(\alpha) \\
\text { [a.u.] }\end{array}$ & $\begin{array}{l}\mathrm{E}_{\text {calc }} \\
{\left[\mathrm{cm}^{-1}\right]}\end{array}$ & Mode & $\begin{array}{l}\mathrm{E}_{\text {quin }} \\
{\left[\mathrm{cm}^{-1}\right]}\end{array}$ & $\begin{array}{l}\text { Sym- } \\
\text { metry }\end{array}$ \\
\hline \multirow[t]{2}{*}{1} & 1604 & 57 & CC-str., CCC-bend. & 1603 & 59 & 1606.5 & CC-str. ${ }^{\mathrm{A}}, \mathrm{CC}$-str. ${ }^{\mathrm{B}}$ & & \\
\hline & & & & & & 1605.4 & CC-str. ${ }^{\mathrm{C}}, \mathrm{CCC}$-bend. ${ }^{\mathrm{C}}$ & & \\
\hline \multirow[t]{3}{*}{2} & 1594 & 23 & CCC-bend., CC-str. & $1594 \mathrm{sh}$ & 27 & 1601.7 & CCC-bend. ${ }^{\mathrm{B}}, \mathrm{CC}$-str. ${ }^{\mathrm{C}}$ & & \\
\hline & & & & & & & & 1592 & $9 A^{\prime}$ \\
\hline & & & & & & 1583.4 & NC-str. ${ }^{\mathrm{A}}, \mathrm{CC}$-str. ${ }^{\mathrm{A}}$ & 1580 & $10 A^{\prime}$ \\
\hline \multirow[t]{2}{*}{3} & 1580 & 89 & NC-str., CC-str. & 1578 & 72 & 1582.4 & NC-str. ${ }^{\mathrm{C}}, \mathrm{CC}$-str. ${ }^{\mathrm{C}}$ & & \\
\hline & & & & & & 1575.7 & NC-str. ${ }^{\mathrm{B}}, \mathrm{CC}$-str. ${ }^{\mathrm{B}}$ & & \\
\hline \multirow[t]{2}{*}{4} & 1509 & 25 & $11 A^{\prime}$ & & & & & 1508 & $11 \mathrm{~A}^{\prime}$ \\
\hline & & & & & & 1503.2 & CC-str. ${ }^{\mathrm{B}}$ & & \\
\hline \multirow[t]{2}{*}{5} & 1498 & 183 & CC-str., CCH-bend. & 1497 & 150 & 1500.6 & CC-str. ${ }^{\mathrm{C}}, \mathrm{CCH}-\mathrm{bend} .^{\mathrm{C}}$ & 1503 & \\
\hline & & & & & & 1499.7 & CC-str. ${ }^{\mathrm{C}}, \mathrm{CCH}$-bend. ${ }^{\mathrm{B}}$ & & \\
\hline 6 & & & & & & 1476.1 & CO-str. ${ }^{\mathrm{A}}, \mathrm{CC}$-str. ${ }^{\mathrm{A}}$ & & \\
\hline 7 & 1473 & 141 & CO-str., CC-str. & 1471 & 96 & 1468.0 & CO-str. ${ }^{\mathrm{C}}, \mathrm{CC}-$ str. $^{\mathrm{A}}$ & 1471 & $12 \mathrm{~A}^{\prime}$ \\
\hline \multirow[t]{2}{*}{8} & 1463 & 76 & CC-str., CO-str. & & & 1462.7 & CC-str. ${ }^{\mathrm{B}}, \mathrm{CO}-$ str. $^{\mathrm{B}}$ & 1471 & $12 \mathrm{~A}^{\prime}$ \\
\hline & & & & & & 1426.9 & CCH-bend. ${ }^{\mathrm{A}}$ & 1434 & $13 \mathrm{~A}^{\prime}$ \\
\hline \multirow[t]{3}{*}{9} & 1421 & 39 & $\mathrm{CCH}$-bend. & 1421 & 17 & 1426.2 & CCH-bend. ${ }^{\mathrm{C}}$ & & \\
\hline & & & & & & 1425.0 & CCH-bend. ${ }^{\mathrm{B}}$ & & \\
\hline & & & & & & & & 1410 & $14 \mathrm{~A}^{\prime}$ \\
\hline \multirow[t]{2}{*}{10} & 1403 & 11 & & & & & & & \\
\hline & & & & & & 1392.3 & NC-str. ${ }^{\mathrm{B}}, \mathrm{NCH}-$ bend. ${ }^{\mathrm{B}}$ & & \\
\hline \multirow[t]{3}{*}{11} & 1384 & 194 & NC-str., NCH-bend. & 1385 & 112 & 1391.4 & NC-str. ${ }^{C}, \mathrm{NCH}-$ bend. ${ }^{\mathrm{C}}$ & & \\
\hline & & & & & & 1389.8 & NC-str. ${ }^{\mathrm{A}}, \mathrm{NCH}-$ bend. ${ }^{\mathrm{A}}$ & & \\
\hline & & & & & & 1376.7 & CC-str. ${ }^{\mathrm{A}}, \mathrm{CC}$-str. ${ }^{\mathrm{B}}$ & 1381 & $15 \mathrm{~A}^{\prime}$ \\
\hline \multirow[t]{3}{*}{12} & 1377 & 143 & CC-str. & 1375 & 117 & 1375.8 & CC-str. ${ }^{\mathrm{C}}, \mathrm{CC}$-str. ${ }^{\mathrm{A}}$ & & \\
\hline & & & & & & 1372.9 & CC-str. ${ }^{\mathrm{B}}, \mathrm{CC}$-str. ${ }^{\mathrm{A}}$ & $1372 s$ & \\
\hline & & & & & & 1337.2 & CCH-bend. ${ }^{\mathrm{A}}, \mathrm{CO}-$ str. $^{\mathrm{A}}$ & & \\
\hline 13 & 1333 & 97 & $\mathrm{CCH}$-bend., CO-str. & 1327 & 86 & 1334.6 & $\mathrm{CCH}-$ bend. ${ }^{\mathrm{B}}, \mathrm{CCH}-$ bend. $^{\mathrm{C}}$ & 1355 & $16 \mathrm{~A}^{\prime}$ \\
\hline
\end{tabular}




\begin{tabular}{|c|c|c|c|c|c|c|c|c|c|}
\hline & & & & & & 1331.2 & CCH-bend. ${ }^{\mathrm{C}}, \mathrm{CO}-$ str. $^{\mathrm{C}}$ & & \\
\hline & & & & & & & & 1285 & $17 \mathrm{~A}^{\prime}$ \\
\hline & & & & & & 1294.3 & NC-str. ${ }^{\mathrm{A}}, \mathrm{CCC}$-bend. ${ }^{\mathrm{A}}$ & & \\
\hline 14 & 1282 & 55 & CO-str., NC-str. CCH-bend. & 1282 & 48 & 1291.7 & NC-str. ${ }^{\mathrm{B}}, \mathrm{CO}$-str. ${ }^{\mathrm{B}}$ & 1276 & $18 \mathrm{~A}^{\prime}$ \\
\hline & & & & & & 1290.1 & CO-str. ${ }^{\mathrm{C}}, \mathrm{CCH}-$ bend. ${ }^{\mathrm{C}}$ & & \\
\hline 15 & 1244 & 25 & CCH-bend. & 1242 & 10 & & $\mathrm{CCH}$-bend. & 1244 & \\
\hline & & & & & & 1229.1 & NC-str. ${ }^{\mathrm{A}}, \mathrm{NCH}-$ bend. ${ }^{\mathrm{A}}$ & & \\
\hline 16 & 1230 & 52 & NC-str., NCH-bend. & 1227 & 54 & 1226.9 & NCH-bend. ${ }^{\mathrm{C}}, \mathrm{NC}$-str. ${ }^{\mathrm{C}}$ & & \\
\hline & & & & & & 1221.6 & NCH-bend. ${ }^{\mathrm{B}}, \mathrm{NC}^{- \text {str. }^{\mathrm{B}}}$ & 1223 & $19 A^{\prime}$ \\
\hline & & & & & & 1216.9 & CC-str. ${ }^{B}$ & 1206 & $20 \mathrm{~A}^{\prime}$ \\
\hline 17 & 1209 & 10 & CC-str. & 1211 & 16 & 1216.3 & CC-str. ${ }^{\mathrm{C}}$ & & \\
\hline & & & & & & 1216.2 & CC-str. ${ }^{A}$ & & \\
\hline & & & & & & & & 1187 & \\
\hline & & & & & & 1169.3 & CCH-bend. ${ }^{\mathrm{C}}, \mathrm{CCH}-$ bend. ${ }^{\mathrm{A}}$ & 1173 & \\
\hline 18 & 1173 & 20 & CCH-bend. & 1173 & 13 & 1168.6 & CCH-bend. ${ }^{\mathrm{B}}$ & 1166 & $21 \mathrm{~A}^{\prime}$ \\
\hline & & & & & & 1168.3 & CCH-bend. ${ }^{\mathrm{A}}$ & & \\
\hline & & & & & & 1134.2 & CCH-bend. ${ }^{\mathrm{C}}$ & 1140 & $22 \mathrm{~A}^{\prime}$ \\
\hline 19 & 1133 & 10 & CCH-bend. & 1133 & 3 & 1135.5 & CCH-bend. ${ }^{\mathrm{A}}$ & & \\
\hline & & & & & & 1133.1 & CCH-bend. ${ }^{\mathrm{B}}$ & & \\
\hline & & & & & & 1105.5 & CCH-bend. ${ }^{\mathrm{A}}, \mathrm{CNC}$-bend. ${ }^{\mathrm{A}}$ & 1113 & \\
\hline 20 & 1111 & 143 & $\mathrm{CCH}$-bend., CNC-bend. & 1112 & 120 & 1104.3 & CCH-bend. ${ }^{\mathrm{C}}, \mathrm{CNC}$-bend. ${ }^{\mathrm{C}}$ & 1099 & $23 A^{\prime}$ \\
\hline & & & & & & 1102.5 & CCH-bend. ${ }^{\mathrm{B}}$, CNC-bend. ${ }^{\mathrm{B}}$ & & \\
\hline & & & & & & 1056.1 & CC-str. ${ }^{\mathrm{A}}$ & & \\
\hline 21 & 1060 & 22 & CC-str. & 1058 & 20 & 1052.0 & CC-str. ${ }^{\mathrm{C}}$ & 1060 & $24 \mathrm{~A}^{\prime}$ \\
\hline & & & & & & 1050.1 & CC-str. ${ }^{\mathrm{B}}$ & & \\
\hline & & & & & & 1034.8 & CC-str. ${ }^{\mathrm{A}}$ & & \\
\hline 22 & 1036 & 70 & CC-str. & 1033 & 47 & 1030.3 & CC-str. ${ }^{\mathrm{C}}$ & 1029 & \\
\hline & & & & & & 1029.1 & CC-str. ${ }^{B}$ & & \\
\hline & & & & & & & & 974 & $1 \mathrm{~A} "$ \\
\hline & & & & & & & & 959 & $2 \mathrm{~A} "$ \\
\hline & & & & & & & & 950 & $3 A^{\prime \prime}$ \\
\hline & & & & & & & & 897 & $26 A^{\prime \prime}$ \\
\hline 23 & & & & 867 & 12 & 868.5 & CC-tors. ${ }^{\mathrm{B}}, \mathrm{C}$-pyr. ${ }^{\mathrm{B}}$ & & \\
\hline 24 & 864 & 31 & CC-tors., C-pyr. & 859 & 19 & 865.6 & CC-tors. ${ }^{\mathrm{C}}, \mathrm{C}$-pyr. ${ }^{\mathrm{C}}$ & 866 & $4 A^{\prime \prime}$ \\
\hline & & & & & & 864.8 & CC-tors. ${ }^{\mathrm{A}}, \mathrm{C}$-pyr. ${ }^{\mathrm{A}}$ & & \\
\hline & & & & & & 826.2 & C-pyr. ${ }^{\mathrm{B}}$ & 818 & $5 \mathrm{~A}^{\prime \prime}$ \\
\hline 25 & 823 & 227 & C-pyr. & 823 & 197 & 824.3 & C-pyr. ${ }^{\mathrm{C}}$ & & \\
\hline & & & & & & 820.2 & C-pyr. ${ }^{A}$ & & \\
\hline & & & & & & 793.2 & CCC-bend. ${ }^{\mathrm{C}}$ & & \\
\hline 26 & 804 & 168 & CCC-bend. & 803 & 152 & 792.4 & CCC-bend. ${ }^{\mathrm{B}}$ & 807 & $27 \mathrm{~A}^{\prime \prime}$ \\
\hline
\end{tabular}




\begin{tabular}{|c|c|c|c|c|c|c|c|c|c|}
\hline & & & & & & 791.7 & CCC-bend. ${ }^{\mathrm{A}}$ & & \\
\hline & & & & & & 787.6 & CC-tors. ${ }^{\mathrm{B}}, \mathrm{C}$-pyr. ${ }^{\mathrm{B}}$ & & \\
\hline \multirow[t]{3}{*}{27} & 788 & 182 & N-pyr., CC-tors. C-pyr. & 786 & 150 & 786.2 & N-pyr. ${ }^{\mathrm{C}}, \mathrm{CC}$-tors. ${ }^{\mathrm{C}}$ & 781 & $6 A^{\prime \prime}$ \\
\hline & & & & & & 784.2 & C-pyr. ${ }^{\mathrm{A}}, \mathrm{CC}$-tors. ${ }^{\mathrm{A}}$ & & \\
\hline & & & & & & 751.8 & C-pyr. ${ }^{\mathrm{B}}$ & & \\
\hline \multirow[t]{3}{*}{28} & $753^{*}$ & 250 & C-pyr. * & 747 & 250 & 750.3 & C-pyr. ${ }^{\mathrm{C}}$ & & \\
\hline & & & & & & 749.1 & C-pyr. ${ }^{A}$ & & \\
\hline & & & & & & 746.0 & OAl-str. ${ }^{\mathrm{A}}, \mathrm{CC}$-str. ${ }^{\mathrm{A}}$ & & \\
\hline \multirow[t]{2}{*}{29} & $747^{*}$ & 239 & OAl-str., CC-str. CCC- & 747 & & 743.2 & OAl-str. ${ }^{\mathrm{C}}, \mathrm{CCC}$-bend. ${ }^{\mathrm{C}}$ & 741 & $7 A^{\prime \prime}$ \\
\hline & & & & & & 741.0 & OAl-str. ${ }^{\mathrm{B}}, \mathrm{CC}$-str. ${ }^{\mathrm{B}}$ & 711 & $28 A^{\prime \prime}$ \\
\hline \multirow[t]{2}{*}{30} & 652 & 98 & N-pyr., CC-tors. & 652 & 111 & 653.4 & N-pyr. ${ }^{\mathrm{C}}, \mathrm{CC}$-tors. ${ }^{\mathrm{C}}$ & & \\
\hline & & & & & & 649.5 & N-pyr. ${ }^{\mathrm{C}}, \mathrm{CC}$-tors. ${ }^{\mathrm{C}}$ & & \\
\hline 31 & 645 & 179 & N-pyr., C-pyr. & 647 & 145 & 648.8 & N-pyr. ${ }^{\mathrm{C}}, \mathrm{C}-$ pyr. $^{\mathrm{A}}$ & & \\
\hline 32 & 638 & 150 & N-pyr. & 640 & 127 & 646.8 & N-pyr. ${ }^{\mathrm{B}}, \mathrm{N}$-pyr. ${ }^{\mathrm{C}}$ & 637 & \\
\hline \multirow[t]{2}{*}{33} & & & & $625 \mathrm{sh}$ & 60 & 639.8 & N-pyr. ${ }^{A}$, COAl-bend. ${ }^{A}$ & & \\
\hline & & & & & & 570.5 & CCC-bend. ${ }^{\mathrm{C}}$, COAl-bend. ${ }^{\mathrm{C}}$ & & \\
\hline \multirow[t]{2}{*}{34} & 574 & 56 & COAl-bend, CCC-bend. & 575 & 46 & 568.8 & COAl-bend. ${ }^{\mathrm{A}}, \mathrm{CCC}-$ bend. $^{\mathrm{A}}$ & 575 & $10 A^{\prime \prime}$ \\
\hline & & & & & & 566.9 & COAl-bend. ${ }^{\mathrm{B}}$, COAl-bend. ${ }^{\mathrm{C}}$ & & \\
\hline 35 & 548 & 174 & OAl-str. & 549 & 144 & 540.4 & OAl-str. ${ }^{\mathrm{B}}, \mathrm{OAl}$-str. ${ }^{\mathrm{C}}$ & 547 & \\
\hline 36 & & & & 542 & 141 & 535.7 & OAl-str. ${ }^{\mathrm{A}}, \mathrm{CCC}$-bend. ${ }^{\mathrm{A}}$ & 543 & $30 \mathrm{~A}^{\prime \prime}$ \\
\hline 37 & $531 *$ & 77 & OAl-str., CCC-bend.* & 522 & 54 & 512.0 & OAl-str. ${ }^{\mathrm{B}}, \mathrm{CCC}$-bend. ${ }^{\mathrm{B}}$ & & \\
\hline & & & & & & 495.6 & CCC-bend. ${ }^{\mathrm{B}}, \mathrm{CCC}$-bend. ${ }^{\mathrm{C}}$ & & \\
\hline \multirow[t]{3}{*}{38} & 501 & 31 & CCC-bend. & 503 & 33 & 493.0 & CCC-bend. ${ }^{\mathrm{B}}, \mathrm{CCC}$-bend. ${ }^{\mathrm{C}}$ & & \\
\hline & & & & & & 490.4 & CCC-bend. ${ }^{\mathrm{A}}$ & 491 & $31 A^{\prime \prime}$ \\
\hline & & & & & & 476.0 & C-pyr. ${ }^{\mathrm{B}}$, NAl-tors. ${ }^{\mathrm{C}}$ & & \\
\hline \multirow[t]{2}{*}{39} & 472 & 21 & NAl-tors., C-pyr., CC-tors., & 471 & 59 & 474.6 & NAl-tors. ${ }^{\mathrm{C}}, \mathrm{N}$-pyr. ${ }^{\mathrm{C}}$ & 471 & $11 \mathrm{~A}^{\prime \prime}$ \\
\hline & & & & & & 473.5 & C-pyr. ${ }^{\mathrm{A}}, \mathrm{CC}$-tors. ${ }^{\mathrm{A}}$ & & \\
\hline 40 & 469 & 23 & N-pyr., NAl-tors. & $465 \mathrm{sh}$ & 35 & 464.3 & N-pyr. ${ }^{\mathrm{C}}$, NAl-tors. ${ }^{\mathrm{C}}$ & 465 & $32 A^{\prime}$ \\
\hline 41 & 452 & 96 & N-pyr. & 454 & 145 & 462.5 & N-pyr. ${ }^{\mathrm{C}}, \mathrm{N}$-pyr. ${ }^{\mathrm{A}}$ & & \\
\hline 42 & 443 & 26 & N-pyr., NAl-tors. & 442 & 69 & 450.3 & N-pyr. ${ }^{\mathrm{C}}$, NAl-tors. ${ }^{\mathrm{C}}$ & & \\
\hline 43 & 423 & 260 & Al-N-str. & 418 & 206 & 433 & Al-N-str. & & \\
\hline 44 & & & & 405 & 49 & 415 & Al-N-str. & & \\
\hline 45 & 397 & 117 & Al-N-str., COAl-bend & 396 & 45 & 407 & Al-N-str. & & \\
\hline
\end{tabular}



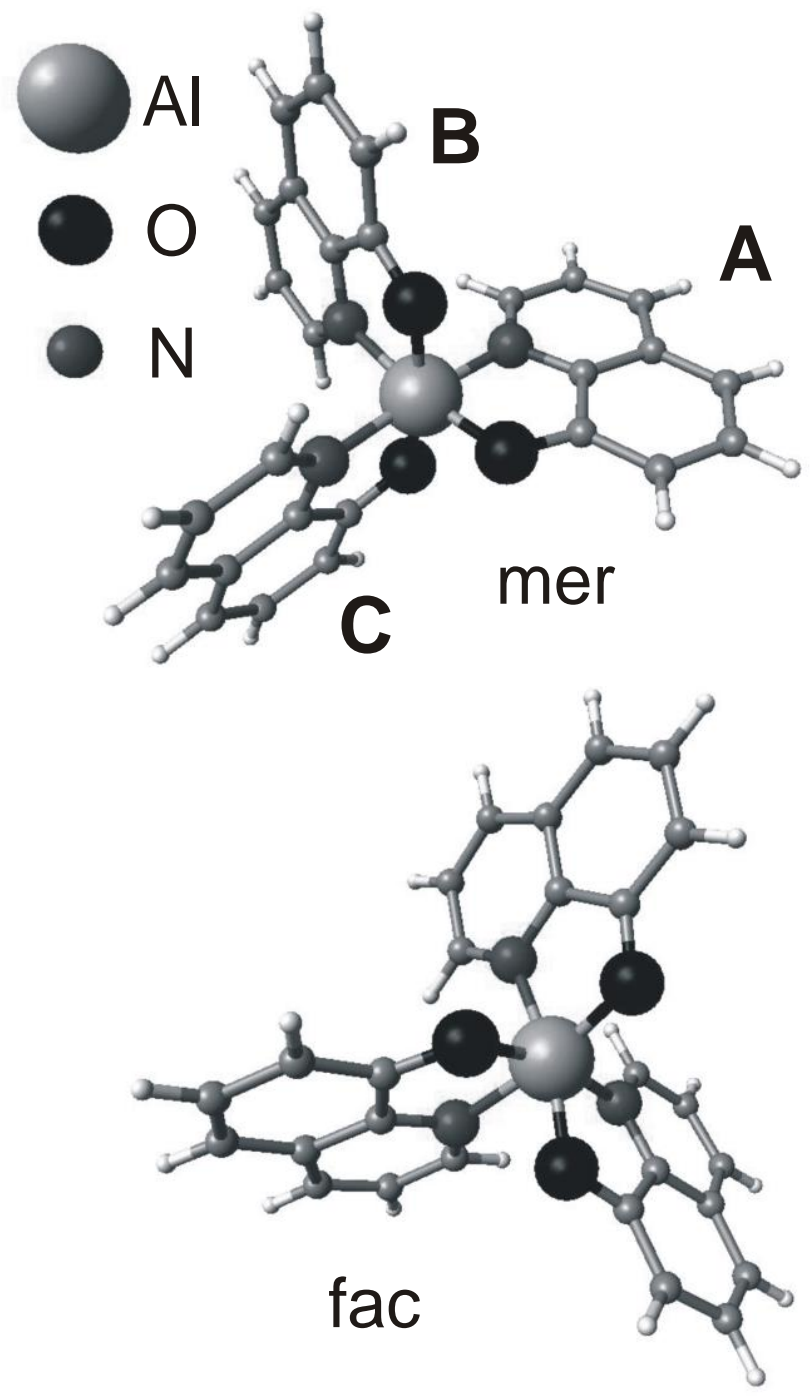

Figure 1. Chemical structure of the two geometrical $\mathrm{Alq}_{3}$ isomers (mer: meridional, fac: facial) and labeling of the three ligands in mer-Alq 3 . 

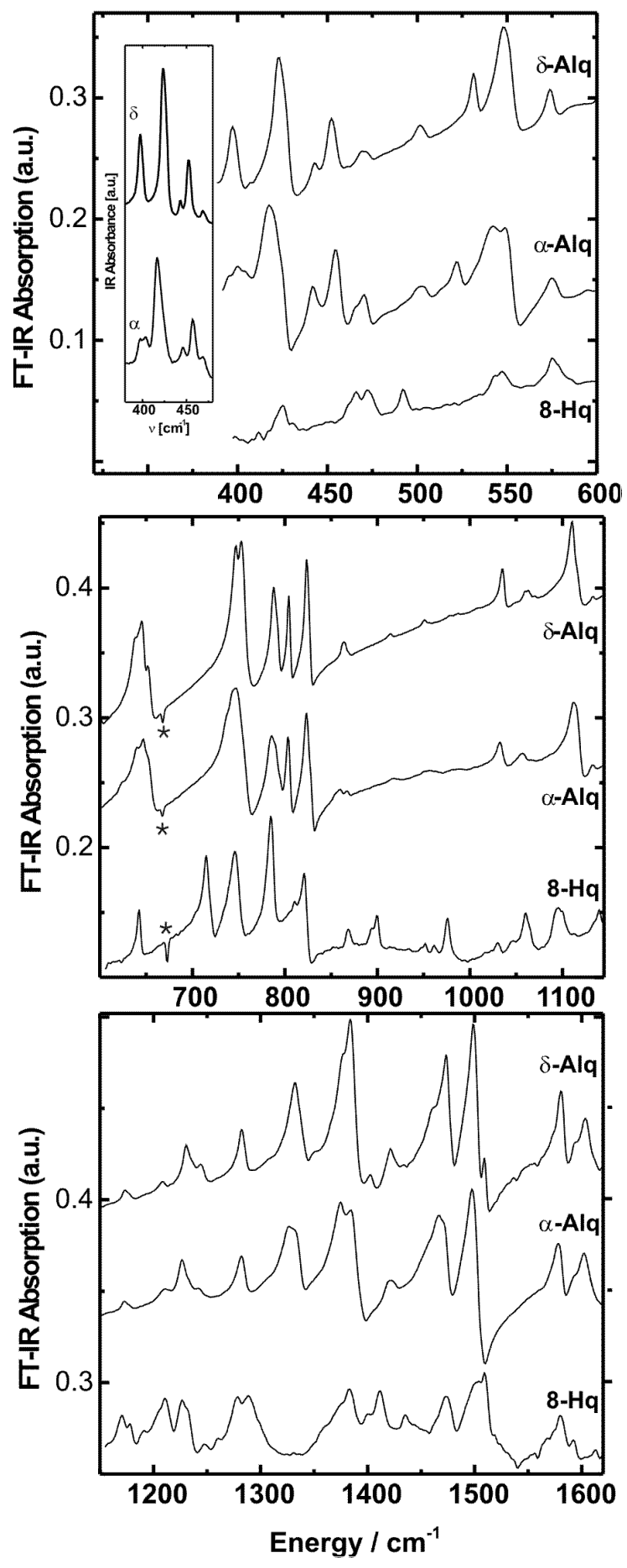

Figure 2: Comparison of the FTIR-spectra of $\delta$-Alq $\mathrm{Al}_{3}$ (upper trace), $\alpha$-Alq 3 (middle trace) and hydoxiquinoline (8-Hq, lower trace) in the range from $350 \mathrm{~cm}^{-1}$ to $1650 \mathrm{~cm}^{-1}$. The inset shows $\alpha-\mathrm{Alq}_{3}$ and $\delta-\mathrm{Alq}_{3}$ in the region between 370 and $480 \mathrm{~cm}^{-1}$ measured with a better resolution below $420 \mathrm{~cm}^{-1}$ due to other beamsplitters *, CsI windows and samples on CsI pellets. The peak marked with an asterisk $(*)$ is an artifact of the setup and is not related to the sample. 


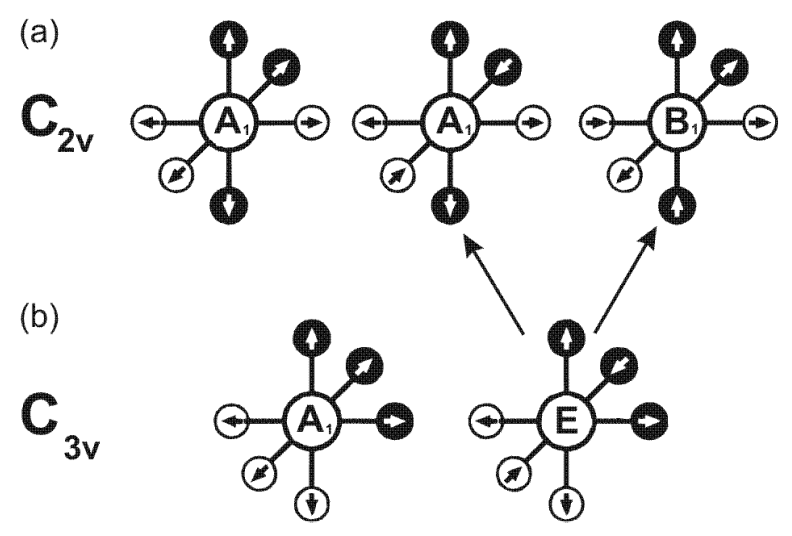

Figure 3: Schematic picture of the central part of the meridional (a) and the facial (b) isomer of Alq. Hollow and filled circles around the central Al-atom stand for oxygen and nitrogen atoms, respectively. The three stretching modes of the meridional molecule $\left(\mathrm{C}_{2 \mathrm{v}}\right.$-symmetry $)$ and the two for the facial molecule $\left(\mathrm{C}_{3 \mathrm{v}}\right.$-symmetry, one is degenerated) are marked with arrows at the $\mathrm{O}$ and $\mathrm{N}$ atoms. 

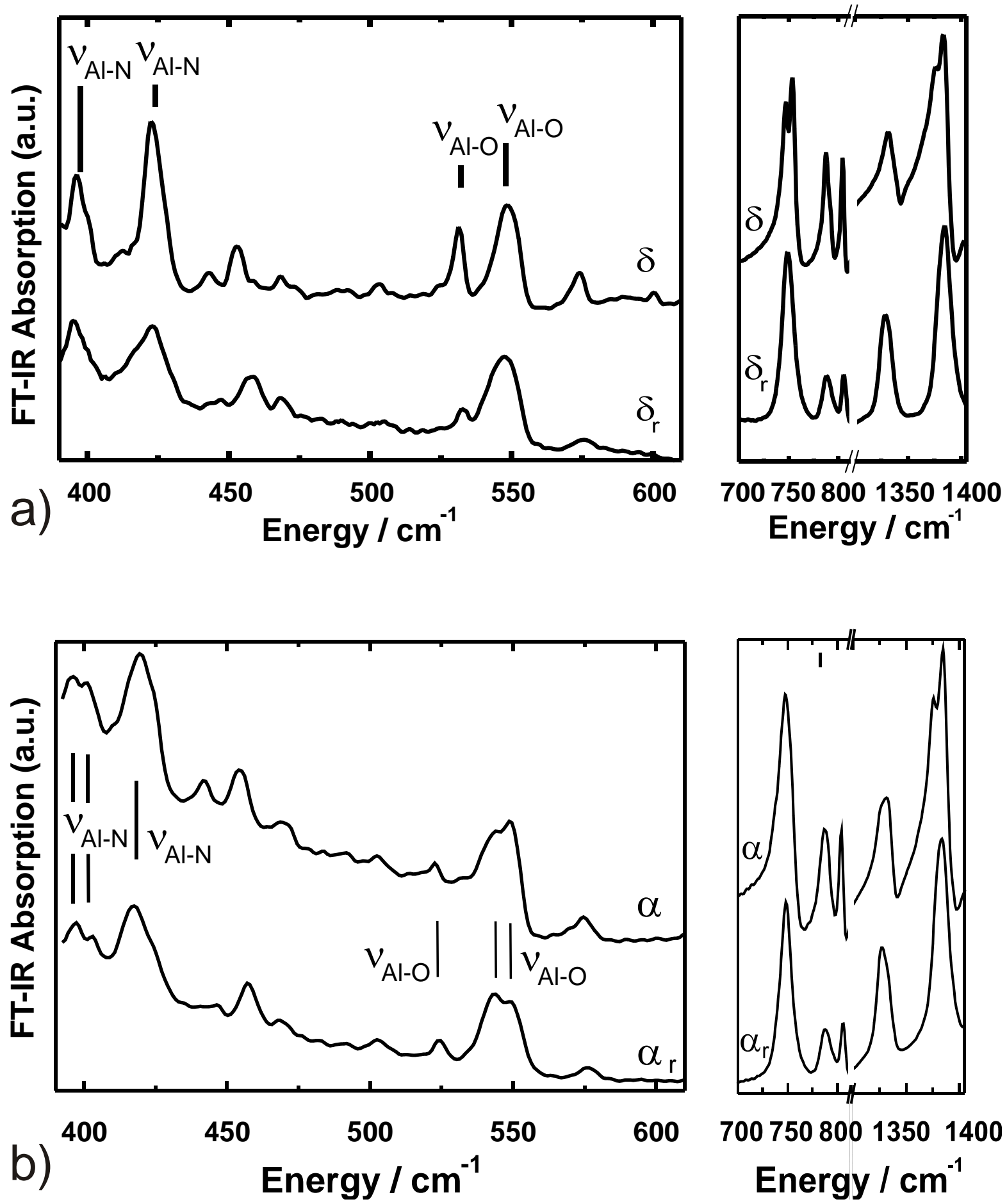
Figure 4: Comparisons of polycrystalline $\mathrm{Alq}_{3}$ as obtained from the sublimation tube and very fine powders of the $\delta$ - and $\alpha$-phases are shown in (a) and (b) respectively. The upper traces shows the polycrystalline samples as prepared and the lower trace the same samples after smoothly rubbing them mechanically, giving a very fine powder. 